\title{
The contribution of $7 q 33$ copy number variations for intellectual disability
}

Fátima Lopes, Fátima Torres, Sally Ann Lynch, Arminda Jorge, Susana Sousa, João Silva, Paula Rendeiro, Purificação Tavares, et al.

neurogenetics

ISSN 1364-6745

Volume 19

Number 1

Neurogenetics (2018) 19:27-40

DOI 10.1007/s10048-017-0533-5

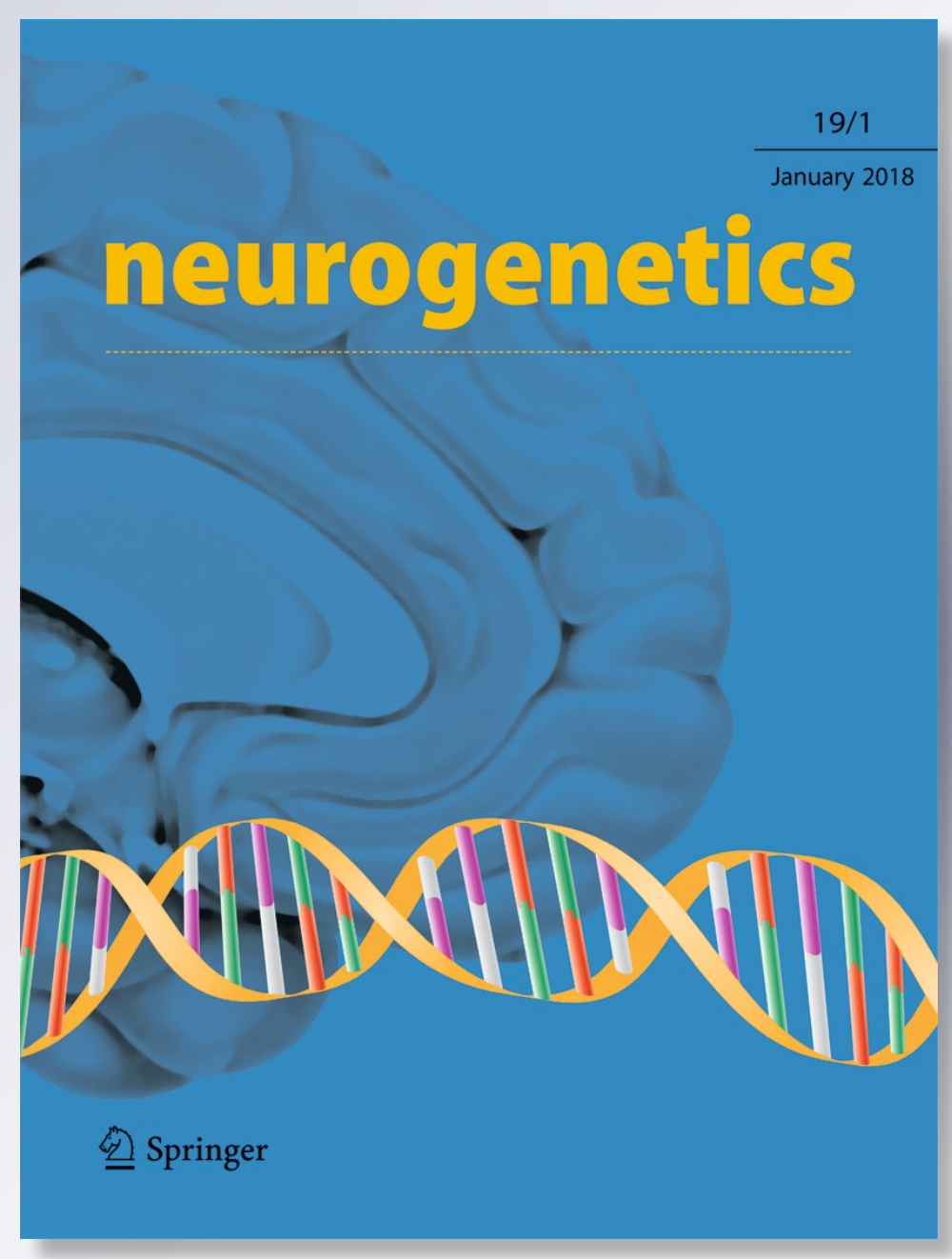

留 Springer 
Your article is protected by copyright and all rights are held exclusively by SpringerVerlag GmbH Germany, part of Springer Nature. This e-offprint is for personal use only and shall not be self-archived in electronic repositories. If you wish to self-archive your article, please use the accepted manuscript version for posting on your own website. You may further deposit the accepted manuscript version in any repository, provided it is only made publicly available 12 months after official publication or later and provided acknowledgement is given to the original source of publication and a link is inserted to the published article on Springer's website. The link must be accompanied by the following text: "The final publication is available at link.springer.com". 


\title{
The contribution of 7q33 copy number variations for intellectual disability
}

\author{
Fátima Lopes ${ }^{1,2}$ - Fátima Torres ${ }^{3,4}$. Sally Ann Lynch $^{5}$ - Arminda Jorge ${ }^{6,7}$ - Susana Sousa ${ }^{1,2} \cdot$ João Silva ${ }^{8}$. \\ Paula Rendeiro ${ }^{3}$ - Purificação Tavares ${ }^{3}$ - Ana Maria Fortuna ${ }^{8}$ - Patrícia Maciel ${ }^{1,2}$ (DD
}

Received: 22 May 2017 / Revised: 28 November 2017 / Accepted: 29 November 2017 / Published online: 19 December 2017

(C) Springer-Verlag GmbH Germany, part of Springer Nature 2017

\begin{abstract}
Copy number variations (CNVs) at the $7 \mathrm{q} 33$ cytoband are very rarely described in the literature, and almost all of the cases comprise large deletions affecting more than just the q33 segment. We report seven patients (two families with two siblings and their affected mother and one unrelated patient) with neurodevelopmental delay associated with CNVs in 7q33 alone. All the patients presented mild to moderate intellectual disability (ID), dysmorphic features, and a behavioral phenotype characterized by aggressiveness and disinhibition. One family presents a small duplication in cis affecting CALD1 and AGBL3 genes, while the other four patients carry two larger deletions encompassing EXOC4, CALD1, AGBL3, and CNOT4. This work helps to refine the phenotype and narrow the minimal critical region involved in $7 \mathrm{q} 33 \mathrm{CNVs}$. Comparison with similar cases and functional studies should help us clarify the relevance of the deleted genes for ID and behavioral alterations.
\end{abstract}

Keywords 7q33 CNVs $\cdot C A L D 1 \cdot A G B L 3 \cdot$ EXOC4 $\cdot$ CNOT4 $\cdot$ Duplication

Fátima Lopes and Fátima Torres contributed equally

Electronic supplementary material The online version of this article (https://doi.org/10.1007/s10048-017-0533-5) contains supplementary material, which is available to authorized users.

Patrícia Maciel

pmaciel@med.uminho.pt

1 Life and Health Sciences Research Institute (ICVS), School of Medicine, University of Minho, Braga, Portugal

2 ICVS/3B's - PT Government Associate Laboratory, Braga/ Guimarães, Portugal

3 CGC Genetics, Porto, Portugal

4 Institute of Biomedical Sciences Abel Salazar (ICBAS), University of Porto, Porto, Portugal

5 Temple Street Hospital, Dublin, Ireland

6 Development Unit, Pediatrics Service, Hospital Centre of Cova da Beira, Covilhã, Portugal

7 CICS - Health Sciences Research Centre, University of Beira Interior, Covilhã, Portugal

8 Center for Medical Genetics Dr. Jacinto Magalhães, Centro Hospitalar do Porto, Porto, Portugal

\section{Introduction}

Interstitial CNVs in $7 \mathrm{q}$ are a rare event and, consequently, poorly characterized. Specifically, there are only 10 reports in the literature of interstitial deletions involving $7 \mathrm{q} 33$. Two cases are deletions ( 7.6 and $7 \mathrm{Mb}$ ) derived from chromosomal translocations [1-3]; one case is a small deletion $(100 \mathrm{~kb})$ affecting only two genes, $A K R 1 B 1$ and $S L C 35 B 4$, in a patient with PHACE syndrome [4]; seven cases show large deletions ranging from cytoband $7 \mathrm{q} 32$ to $7 \mathrm{q} 35$ [5-11]. A deletion affecting $7 \mathrm{q} 33$ only was reported as an abstract but made no mention of the deletion size and genes affected [7]. The two most recent reports in the literature regarding interstitial $7 \mathrm{q}$ deletions describe genomic losses in a patient with intellectual disability (ID), language delay, and microcephaly [12] and in a patient with ID and dysmorphisms [11]. Not surprisingly, given the variable sizes of the deletions and duplications in all the reported cases, there is a widely variable phenotypic presentation, most likely due to the large number of genes involved in these variants. A summary of these reports is presented in Table 1.

It is possible to identify several interesting genes that could account for the ID/developmental delay (DD) phenotype associated with $7 \mathrm{q} 33 \mathrm{CNVs}$, among which are EXOC4 (exocyst complex component 4), CNOT4 (CCR4-NOT transcription 


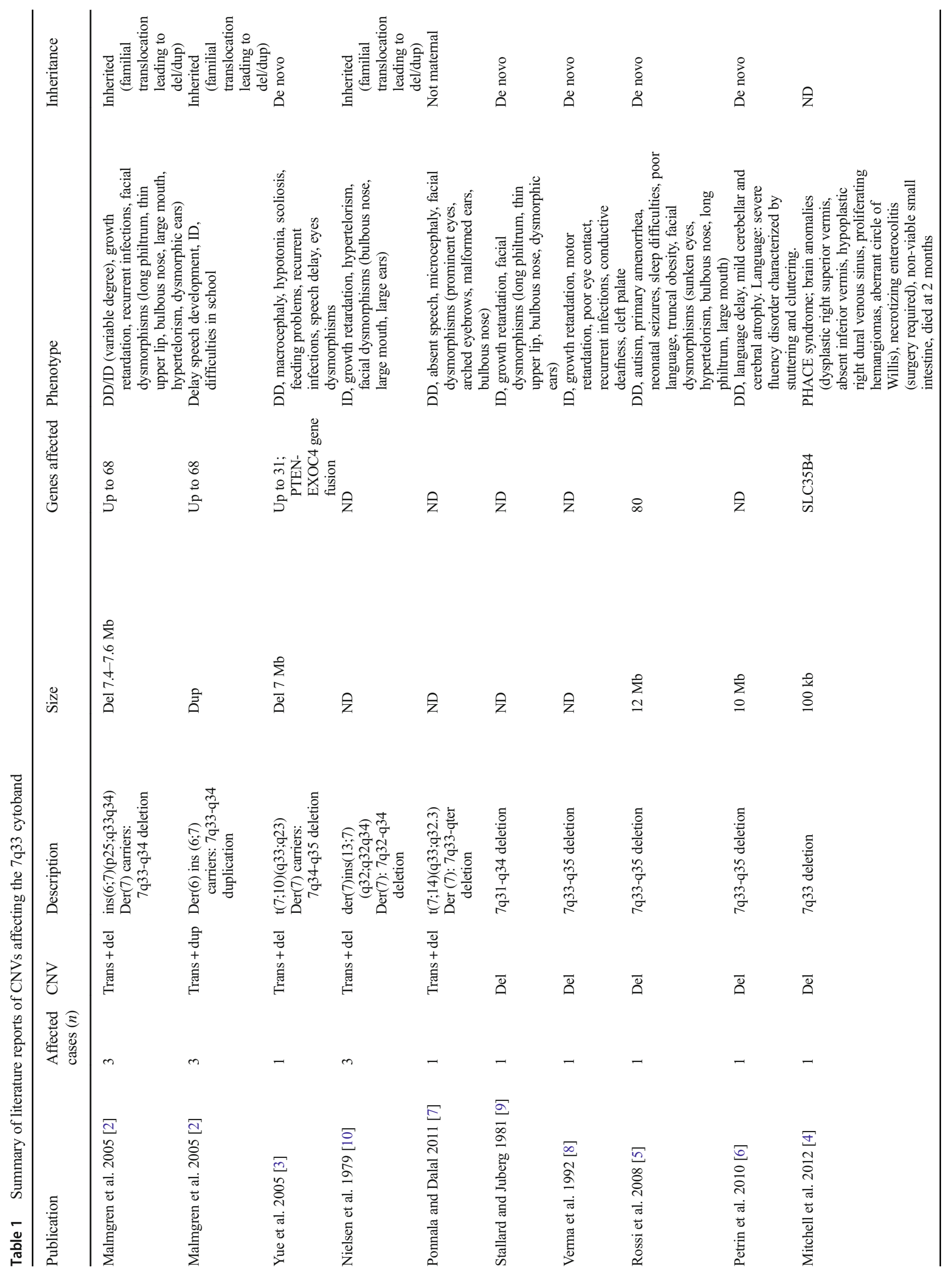


complex, subunit 4), CALD1 (Caldesmon 1), and AGBL3 (ATP/GTP binding protein-like 3). Genotype-phenotype correlations in patients can help define the most relevant genes in this perspective.

In this report, we describe the clinical and genetic findings of seven patients with $7 \mathrm{q} 33$ copy number variations (CNVs) and extend the phenotypic spectrum of $7 \mathrm{q} 33$ interstitial CNVs. We also propose that $C A L D 1$ and $A G B L 3$ are major contributors for the ID phenotype of these patients.

\section{Methods}

\section{Patients}

Patients 1-3 and 5-7 were ascertained within a large study of neurodevelopmental disorders in Portugal, in which the enrollment of the patients and families was done by the referring doctor. Clinical information was gathered in an anonymous database authorized by the Portuguese Data Protection Authority (CNPD). The study was approved by the ethics committee of Center for Medical Genetics Dr. Jacinto Magalhães, National Health Institute Dr. Ricardo Jorge.

Written informed consent was obtained for all participants involved in this publication for the genetic and gene expression studies, blood collection, and for publication of results (including photos).

\section{Molecular karyotyping}

Genomic DNA was extracted from peripheral blood using Citogene ${ }^{\circledR}$ DNA isolation kit (Citomed, Portugal) for patients 1, 2, and 3 and QIAsymphony SP (QIAGEN GmbH, Germany) for patients 5, 6, and 7. The aCGH analysis was performed using aCGH Agilent $180 \mathrm{~K}$ custom array design, accessible through the gene expression omnibus GEO accession number GL15397, for patients 1, 2, and 3 (according to the previously published protocol and the across-array methodology [14, 15]; Agilent $44 \mathrm{~K}$ oligo for patient 4; Affymetrix CytoScan $750 \mathrm{~K}$ platform for patients 5 and 7. aCGH data was analyzed using Nexus Copy Number 5.0 software with FASST Segmentation algorithm for patients 1, 2, and 3; DNA Analytics v4.0.76 for patient 4; Analysis Suite (ChAS 3.0) software for patients 5 and 7 .

\section{Quantitative PCR confirmations}

Primers for qPCR were designed using Primer3Plus software (http://www.bioinformatics.nl/cgi-bin/primer3plus/ primer3plus.cgi) and taking into account standard recommendations for qPCR primer development [16]. A set of primers was designed for exon 10 of the CNOT4 gene (NM_001008225) and for exon 4 of the CALD1 gene (NM 
033138). The reference genes used were SDC4 (NM 002999) and ZNF80 (NM_007136) localized in the 20q12-q13 and 3 p12 regions, respectively. qPCR reactions were carried out in a 7500-FAST Real-Time PCR machine (Thermo Fisher Scientific, Waltham, MA, USA) using Power SYBR Green ${ }^{\circledR}$ (Thermo Fisher Scientific, Waltham, MA, USA). The specificity of each of the reactions was verified by the generation of a melting curve for each of the amplified fragments. The primer efficiency was calculated by the generation of a standard curve fitting the accepted normal efficiency percentage. Quantification was performed as described elsewhere [17]. Ct values obtained for each test were analyzed in DataAssist TM software (Thermo Fisher Scientific, Waltham, MA, USA). First-strand complementary DNA (cDNA) was synthesized using SuperScript ${ }^{\circledR}$ III Reverse Transcriptase (RT) (Thermo Fisher Scientific, Waltham, MA, USA).

\section{FISH analysis}

FISH was performed in metaphase chromosome spreads from cultured peripheral blood cells from patient 6 . The FISH probe was generated using the BAC clone RP11-615F13 (Empire Genomics, Buffalo, NY, USA) and labeled with Green 5Fluorescein dUTP. Analysis was performed according to the manufacturer's indication, and the fluorescence signals were captured using an Isis Fluorescence Imaging System, MetaSystems (Altlussheim, Germany).

\section{Gene fusion exploratory analysis}

Total RNA isolation and cDNA synthesis was performed as described above. In order to determine the presence of a fusion gene at the breakpoints of the $7 q 33$ duplication described in patients 5 and 6 , a set of primers were designed for amplification and sequencing of possible gene fusions, namely those linking $C A L D 1$ exon 4 with $A G B L 3$ exon 16 and $A G B L 3$ exon 16 with $C A L D 1$ exon 4 . The fragments were amplified by PCR and sequenced on an automated DNA-sequencer ABI 3730 XL DNA Analyzer (Thermo Fisher Scientific, Waltham, MA, USA).

\section{Results}

\section{Clinical description}

\section{Patients 1, 2, and 3}

The proband of the first family (patient 1) is a male who was evaluated at 12 years of age for psychomotor delay, ID, and dysmorphic features. Parents are nonconsanguineous and the delivery was uncomplicated, with normal growth parameters. At the time of the first consultation, he had short stature, weight was in the 25 th centile, and the occipitofrontal circumference (OFC) was in the 75 th centile. Evaluation with the Wechsler Intelligence Scale for Children (third edition) [18] was performed at childhood and showed a full-scale IQ of 42, associated with behavioral changes such as aggressiveness, hyperactivity, and disinhibition. The patient is currently 24 years old. He is dysmorphic, with a bulbous and snub nose (with concave root of the nose), down-slanting palpebral fissures, epicanthic folds, deep set eyes, thin upper lip, poor dental implantation and narrow cleft palate, dysplastic and posteriorly rotated ears, and prognathism (Fig. 1a). Additionally, he also has bushy eyebrows, spiky hair with a frontal cowlick, and two hair whorls at the forehead. The hands present light membranous syndactyly of the second to third digits and feet with brachydactyly, sandal gap, and fetal pads. Brain magnetic resonance imaging (MRI) detected a perivascular space enlargement while the echocardiogram and abdominal ultrasound retrieved no abnormalities.

Patient 2 (patient 1's sister) was observed for the first time at 19 years of age. Pregnancy and delivery were uncomplicated. At the time of the clinical evaluation, she presented short stature, weight was in the 95th centile, and OFC was in the 75 th centile. She presented several dysmorphic features, similar to the brother's: snub nose with a concave root, bushy eyebrows, spiky hair with a frontal cowlick and two hair whorls at forehead, deep set eyes, epicanthic folds, thin upper lip, and poor dental implantation (Fig. 1b). She also had a short neck; narrow palate; and small dysplastic ears, posteriorly rotated. Abnormalities of the hands and feet included light membranous syndactyly and brachydactyly, respectively. Computed tomography (CT) scanning, echocardiogram, and abdominal ultrasound showed no abnormalities. Evaluation with the Wechsler Intelligence Scale for Children (third edition) showed a full-scale IQ of 62 . Currently, she is 29 years old. Concerning behavior, she presents aggressiveness (similar to her brother) and disinhibition.

Patient 3 is the mother of patients 1 and 2. She has some clinical features similar to the daughter, such as facial dysmorphic features (milder) and brachydactyly (Fig. 1c). She has mild ID, although no formal neuropsychological evaluation was performed; she did not complete the fourth grade of school but she has the ability to do household chores.

\section{Patient 4}

Patient 4 was born at term to unrelated parents that are phenotypically normal. He was noted to be dysmorphic at birth and was admitted to the hospital because of 
Fig. 1 Facial features of the patients
A

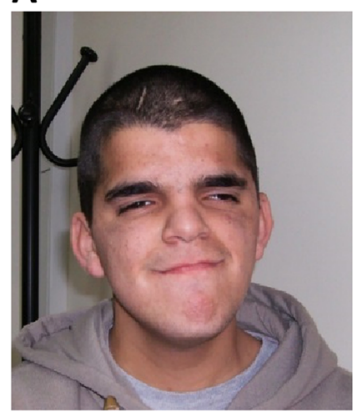

Patient 1

D

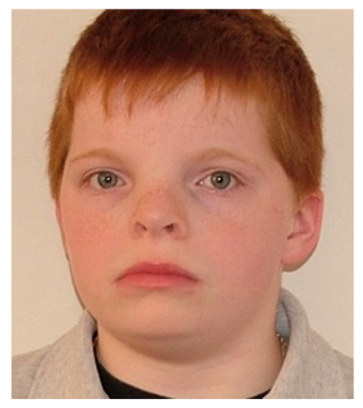

Patient 4
B

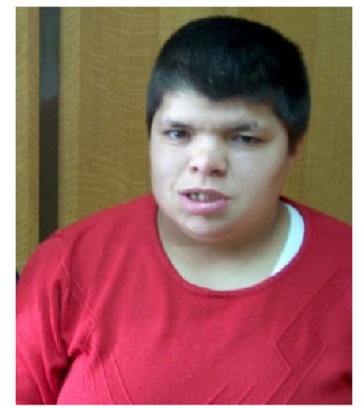

Patient 2

E

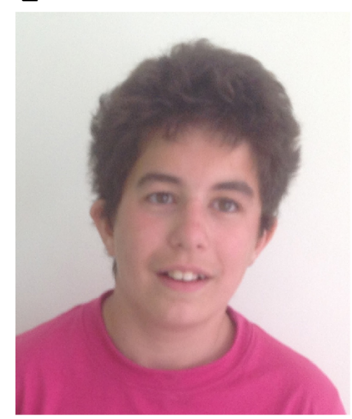

Patient 5
C

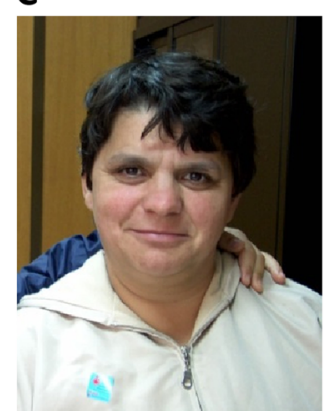

Patient 3

F

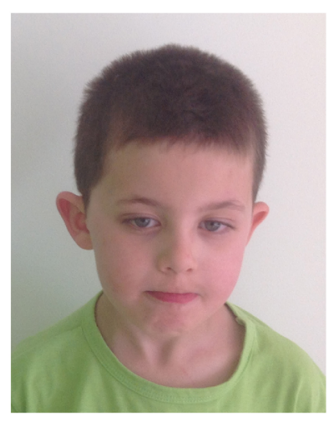

Patient 6 respiratory grunting. He had feeding problems early on. At 4 months of age, a right inguinal hernia was detected. He was noted to have a wide open anterior fontanelle at 8 months. Otitis media developed and a congenital meatal stenosis required meatoplasty at age 4 years. An evaluation at 10 years old revealed that he weighed $39.75 \mathrm{~kg}$ (centile 75 ) and had a height of $139.8 \mathrm{~cm}$ (centile 50) and an OFC of $57.2 \mathrm{~cm}$ (all within normal parameters) (Fig. 1d). Currently, he has hypertelorism and myopia. Behavioral issues were noticed at 4 years of age and he was referred to Child Psychiatry. His attention span was poor. He had aggressive outbursts, unpredictable behavior, and used bad language. He also presented a low frustration threshold, was impulsive, and with oppositional behavior. Currently, he has poor peer relationships (has no friends); he still has odd habits regarding feeding (concerns about bacteria on food) and is preoccupied with germs, death, bugs, and smells. He had a diagnosis of attention deficit and hyperactive disorder (ADHD) and developmental dyspraxia at age 11 years. He also has a tendency to be disinhibited.

\section{Patients 5, 6, and 7}

The proband of this family (patient 5) was evaluated at 11 years of age. Parents are non-consanguineous and delivery was uncomplicated, with normal somatometric parameters (at birth and now). He currently presents moderate ID $(\mathrm{IQ}=54)$, associated with behavioral alterations (opposition, lack of attention, impulsiveness, and sexual disinhibition). He does not have significant facial dysmorphisms besides strabismus.

Patient 6 (patient 5's brother) is a 9-year-old boy with mild ID (IQ =67) and aggressive behavior. He presents normal weight, height, and OFC (at birth and currently) and does not have significant facial dysmorphisms. He is short sighted (myopia).

Their parents were described as having learning difficulties at school. The mother (here referred as patient 7 ) has a documented ID (IQ $<60$ at 20 years of age), a psychiatric disorder (emotional lability, obsessive behavior), and epilepsy. Although the father was not formally evaluated in the consultation by the responsible physician, he is described as healthy. Due to the mother's health condition, patients 5 and 6 currently live in an institution, since the mother does not have the intellectual and behavioral ability to take care of them. The facial appearance of patients 5 and 6 is presented in Fig. 1e, f.

A clinical comparison between the cases is presented in Table 2.

\section{Molecular findings}

aCGH

aCGH in patient 1 revealed a maternally inherited $2.08 \mathrm{Mb}$ deletion at chromosome region 7q33 (chr7:133,176,651135,252,871, hg19) containing 15 genes (according to the DECIPHER database) [19]. A qPCR assay for the CNOT4 


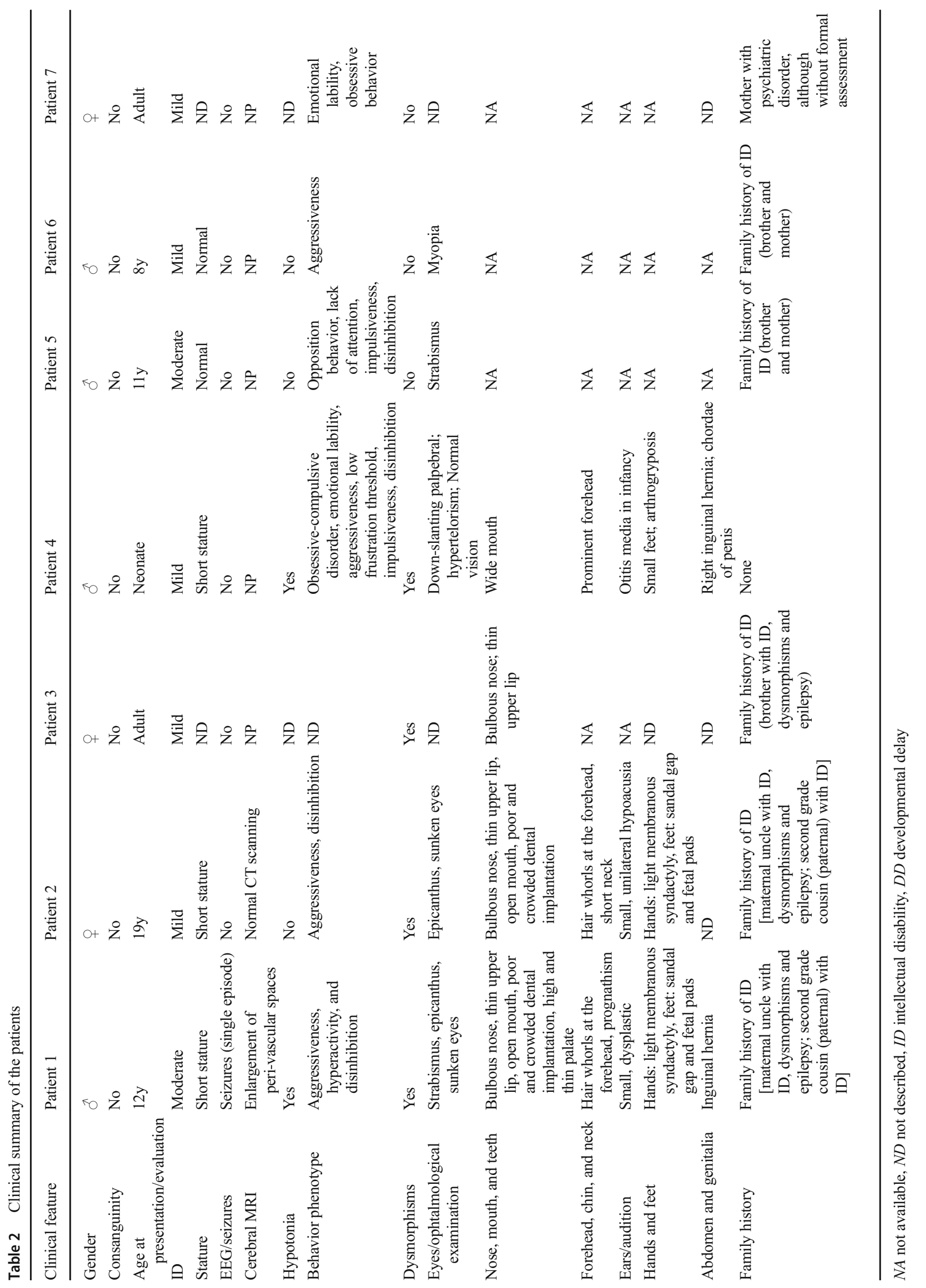


gene was designed and used for validation and determination of the copy number of the region in the sister and both parents, confirming the presence of only one copy of the segment in the patient, sister, and mother. The father presented two copies for the analyzed segment.

Patient 4 was found to carry a de novo $3.04 \mathrm{Mb}$ deletion at chromosome region 7q33 (chr7:132,766,730-135,802,894, hg19) containing 21 genes (according to the DECIPHER database).

Patient 5 presented a $216 \mathrm{~kb}$ maternal duplication at $7 \mathrm{q} 33$ region (chr7:134,598,205-134,807,358, hg19) containing three genes (CALD1, AGBL3, and C7orf49). A qPCR assay for the $C A L D 1$ gene was designed and used for validation of the copy number of the region in the patient and both parents and for the determination of the CNV in his brother, confirming the presence of three copies of the fragment in patients 5,6, and 7 (mother). The father presented two copies for the analyzed fragment (a result concordant with the aCGH). Patient 5 also performed a targeted exome sequencing comprising 4813 genes associated with known clinical phenotypes based on the OMIM database, but no significant pathogenic variants were identified.

A comparison between the molecular alterations identified in the reported patients is presented in Fig. 2 and Table 3.

\section{FISH results}

FISH analysis in patient 6 revealed a signal in chromosome 7 that is indicative of the presence of the duplication in tandem, excluding a location in another chromosome (Fig. 3d).

\section{Fusion transcript results}

Considering that, according to Newman and colleagues, most of the duplications' CNVs are in tandem and could originate fusion genes at the breakpoints [20], we have designed a set of assays in order to test for the presence of such chimeric transcripts. A fusion transcript between $A G B L 3$ exon 16 and $C A L D 1$ exon 4 was detected in patients 5 and 6 (Fig. 3e). This finding is in agreement with the FISH analysis and also indicates that the duplication is not inverted. This hypothesis was also reinforced by the fact that it was not possible to amplify any PCR products indicative for an inverted duplication in patient 5 (Fig. 3e). According to our analysis, the identified AGBL3-CALD1 gene fusion transcript would lead to an out of frame protein from $C A L D 1$ on (Fig. 3f).

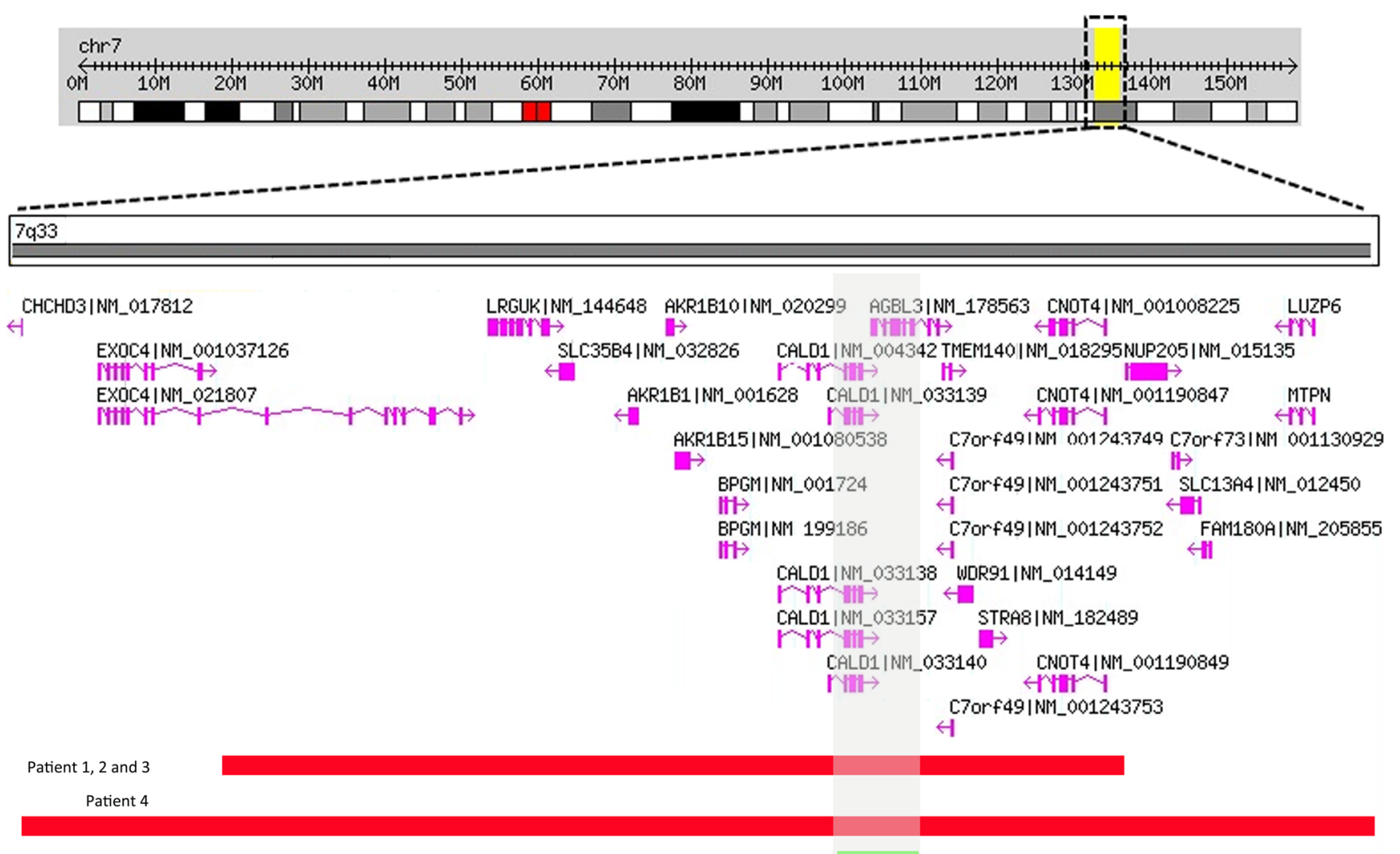

Patient 5, 6 and 7

Fig. 2 Schematic representations and overlap of the CNVs found in the patients. A $3 \mathrm{Mb}$ genomic portion of the cytoband 7q33 is shown. RefSeq genes present within the genomic region (in pink; transcriptional direction represented by the arrows) are shown. The overlapping deleted region for all the patients is shaded in gray. Individual red horizontal bars represent deletions. In each $\mathrm{CNV}$, the corresponding patient is indicated 


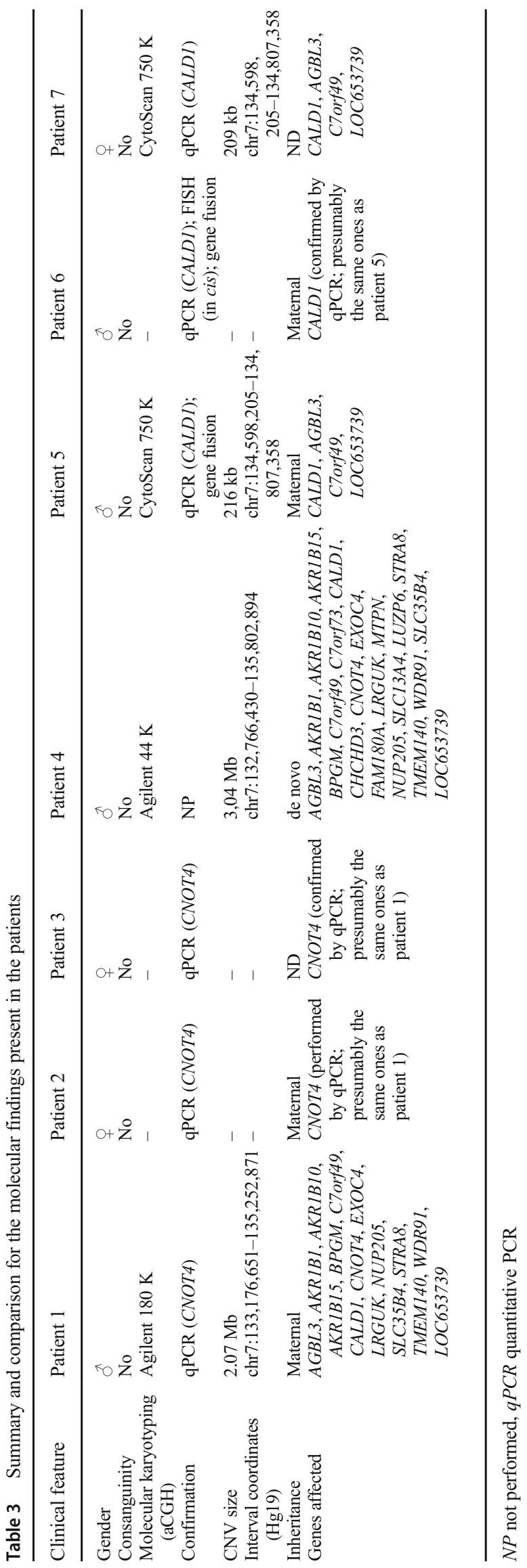

\section{Constraint metrics}

Several constraint metrics for all the 21 genes affected in patient 4 (with the larger CNV) are presented in Table 4. EXOC4 and CNOT4 are two of the genes with the highest ranks in the haploinsufficiency score (predicted probability of exhibiting haploinsufficiency); the data was retrieved from DECIPHER database, where the score was determined using the classification model published by Huang et al. [21]).

\section{Discussion}

While $7 \mathrm{q} 33 \mathrm{CNV}$ s are rare events, several interstitial deletions of chromosome $7 \mathrm{q}$ have been described in the recent past ranging from 7.6 to $13.8 \mathrm{Mb}$ in size all $[2,5,6,11,12]$. In this work, we report seven patients (from three families) with $7 \mathrm{q} 33 \mathrm{CNVs}$, all affecting at least the CALD1 and AGBL3 genes (Fig. 2 and Tables 2 and 3). Patients 5, 6, and 7 all present a small $216 \mathrm{~kb}$ duplication affecting the CALD1, $A G B L 3$, and $C 7$ orf 49 genes, confirmed by FISH analysis to be in tandem and to lead to the formation of a fusion gene (Fig. 3e). This type of chimeric genes can be related to clinical phenotypes [20]. In fact, an enrichment of rare, brainexpressed chimeric genes was observed in individuals with schizophrenia, with functional studies suggesting a disrupting effect of these fusion genes in critical neuronal pathways [22]. Because both breakpoints occur in intronic regions, the genes are fused by $A G B L 3$ intron 15 and $C A L D 1$ intron 3, leading to a fused transcript between $A G B L 3$ exon 16 and $C A L D 1$ exon 4 without any apparent compromise of exonic regions (Fig. $3 \mathrm{~b}, \mathrm{f})$. The variable amplification of the chimeric messenger RNA (mRNA) indicates that the fused transcript is likely to be degraded, though not completely, since we were able to amplify it in one of the samples collected from patient 5 , but not in the other. Also, for patient 6, the fusion transcript was only possible to amplify in the first sample collected using a nested PCR protocol (Fig. 3e). The transcript was also not possible to detect in cultured blood cells for patient 6 . This variability in the degradation of the product is not surprising, as it has been described before in a very similar study [23].

Nevertheless, and since the degradation of the AGBL3$C A L D 1$ chimeric gene does not appear to be complete, it is plausible that it might also contribute for the phenotype, since it could interfere with parent gene function [22].

Additionally, although the pathogenic contribution of the chimeric $A G B L 3-C A L D 1$ gene cannot be excluded, the detected rearrangement could also impair the individual expression of both the $A G B L 3$ and $C A L D 1$ genes.

The AGBL3 (ATP/GTP binding protein-like 3) gene encodes a cytosolic carboxypeptidase (CCP3) that is able to mediate both the deglutamylation and deaspartylation of tubulin [24]. The deglutamylation of tubulin plays an important 
A Reference CALD1

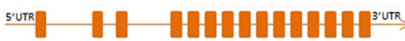

\section{AGBL3}

\section{sore}

B If duplicated in tandem in direct orientation

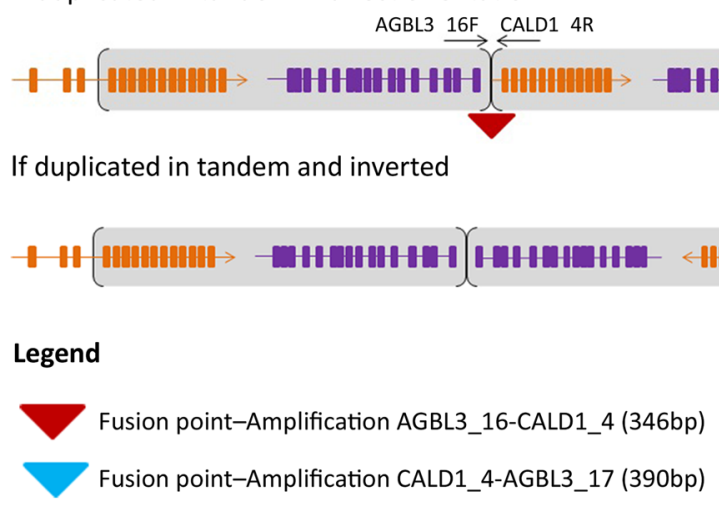

D

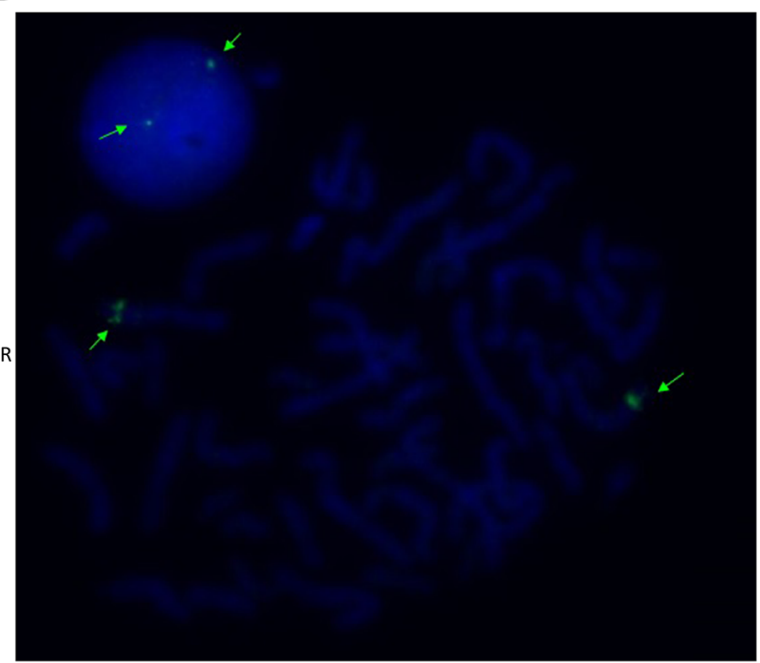

E

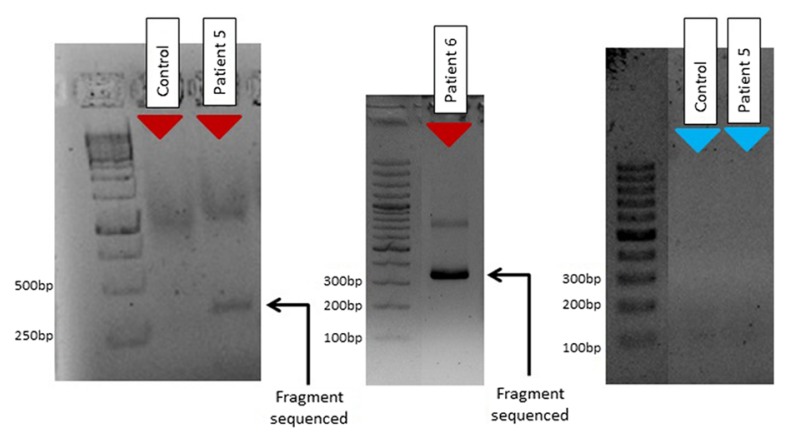

$\mathbf{F}$

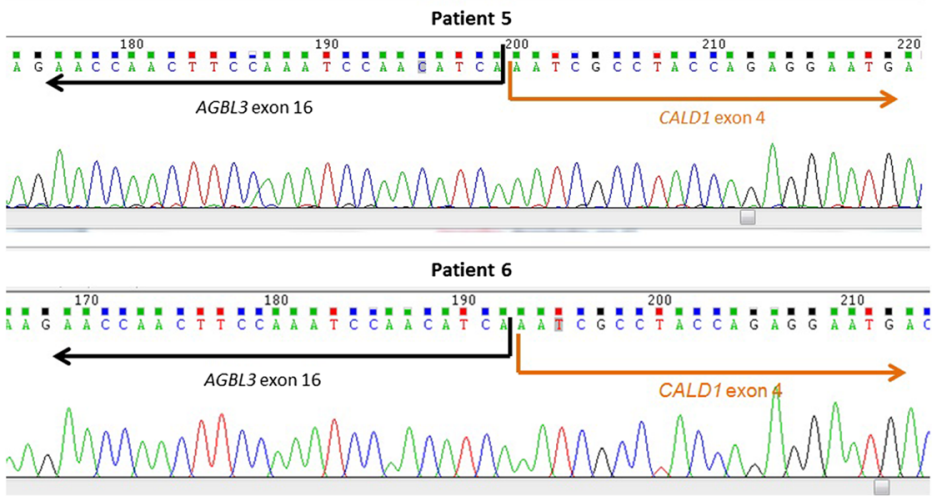

Fig. 3 Schematic representation of $C A D L 1$ and $A G B L 3$ genes at the $7 \mathrm{q} 33$ cytoband. a Schematic representation of the normal location of $C A D L 1$ and $A G B L 3$ genes. b The hypothesis that the duplicated region (highlighted in gray) is located in tandem and not inverted is represented, which would hypothetically lead to the formation of a gene fusion between $A G B L 3$ and $C A L D 1$. $\mathbf{c}$ The hypothesis that the duplicated region (highlighted in gray) is located in tandem and inverted is represented, which would hypothetically lead to the formation of a gene fusion between $A G B L 3$ and $A G B L 3$ and between $C A L D 1$ and $A G B L 3$. The red triangle represents the possible fusion between $A G B L 3$ and $C A L D 1$ (in the "in tandem not inverted" scenario), the green triangle the possible fusion between $A G B L 3$ and $A G B L 3$, and the blue triangle the possible fusion between $C A L D 1$ and $A G B L 3$ (in the "in tandem

role in regulation of the microtubule cytoskeleton, of known relevance for neurons; in fact, the control of the length of the polyglutamate side chains linked to tubulin was shown to be critical for neuronal survival [25], which would make this gene a possible contributor to the patients' phenotype. However, and although tubulin is a key protein in regulation of the microtubule cytoskeleton and this is of known relevance for neurons [25], there is not enough evidence that $A G B L 3$ does have a function in cytoskeleton regulation in neurons. In fact, according to the GTEx portal [26], AGBL3 has very low expression in most of the tissues in human, with only the testis presenting a slightly higher expression at the mRNA level [24, inverted" scenario). d FISH analysis for the duplicated region using the BAC clone FISH probe RP11-615F13 located in CALD1 gene where it is possible to observe a signal indicative of the presence of the duplication in tandem (arrow). e PCR amplification of potential fusion products from patients' and controls' cDNA. Only the PCR product corresponding to the $A G B L 3$ and $C A L D 1$ fusion transcript was possible to amplify (indicated by the arrow) in patients 5 and 6 . The absence of a PCR product for both control and patient 5's cDNA on the right (blue triangle) is not in support of the presence of this fusion product ("duplication inverted"). f Sanger sequencing of the PCR fragment amplified by AGBL3_16F and CALD1_4R revealed that $A G B L 3$ exon 16 and $C A L D 1$ exon 4 were fused at the cDNA pf patient 5

26]. Therefore, the contribution of this gene to the ID phenotype is actually unclear.

The other gene affected by this rearrangement is CALD1 (Caldesmon1) which encodes for the caldesmon protein and is widely expressed, including in the nervous system. Caldesmon is an actin-linked regulatory protein that binds and stabilizes actin filaments and regulates actin-myosin interaction playing an important role in cell motility regulation [27]. Since caldesmon has numerous functions in cell motility (such as migration, invasion, and proliferation), executed through the reorganization of the actin cytoskeleton [28], its alteration is likely to have a functional contribution for ID 
Table 4 OMIM entrance, haploinsufficiency score, and constraint metrics for the genes deleted in patient 4 (the largest deletion)

\begin{tabular}{|c|c|c|c|c|c|c|c|c|c|}
\hline \multirow{3}{*}{$\begin{array}{l}7 \mathrm{q} 33 \\
\text { Gene }\end{array}$} & \multirow{3}{*}{$\begin{array}{l}\text { List of all the } \\
\text { genes affected } \\
\text { in P4 } \\
\text { Morbid gene }\end{array}$} & \multicolumn{8}{|c|}{$\begin{array}{l}\text { AGBL3, AKR1B1, AKR1B10, AKR1B15, BPGM, C7orf49, C7orf73, CALD1, CHCHD3, } \\
\text { CNOT4, EXOC4, FAM180A, LRGUK, MTPN, NUP205, SLC13A4, LUZP6, STRA8, } \\
\text { TMEM140, WDR91, SLC35B4 }\end{array}$} \\
\hline & & \multirow[t]{2}{*}{ OMIM } & \multirow{2}{*}{$\begin{array}{l}\text { HI } \\
\text { score } \\
\%\end{array}$} & \multirow[t]{2}{*}{ DDG2P } & \multirow[t]{2}{*}{ ClinVar } & \multicolumn{4}{|c|}{ Constraint metrics } \\
\hline & & & & & & $\begin{array}{l}\text { Synonymous } \\
(\mathrm{z})\end{array}$ & $\begin{array}{l}\text { Missense } \\
\text { (z) }\end{array}$ & $\begin{array}{l}\mathrm{LoF} \\
(\mathrm{pLI})\end{array}$ & $\begin{array}{l}\mathrm{CNV} \\
(\mathrm{z})\end{array}$ \\
\hline$A G B L 3$ & No & - & $64.11 \%$ & - & 10dels/11dups & - & - & - & - \\
\hline$A K R 1 B 1$ & No & - & $25.64 \%$ & - & 9dels/10dups & -0.32 & 0.27 & 0 & -2.25 \\
\hline$A K R 1 B 10$ & No & - & $77.14 \%$ & - & 9 dels/11dups & -0.28 & -0.27 & 0 & -4.12 \\
\hline$A K R 1 B 15$ & No & - & $85.40 \%$ & - & 9dels/11dups & 0.02 & -1.03 & 0 & -3.36 \\
\hline$B P G M$ & Yes & $\begin{array}{l}\text { 222800, erythrocytosis due to } \\
\text { bisphosphoglycerate mutase } \\
\text { deficiency, AR }\end{array}$ & $22.09 \%$ & - & $11 \mathrm{dels} / 11 \mathrm{dups} / 1 \mathrm{SNV}$ & 0.16 & 0.77 & 0.13 & 0.5 \\
\hline C7orf49 & No & - & $80.37 \%$ & - & 10dels/11dups & -0.13 & -0.36 & 0.34 & 0.56 \\
\hline C7orf73 & No & - & $24.71 \%$ & - & 11dels/11dups & - & - & - & - \\
\hline$C A L D 1$ & No & - & $20.28 \%$ & - & 10dels/11dups & 1.02 & -0.14 & 1 & 0.73 \\
\hline CHCHD3 & No & - & $6.30 \%$ & - & 9dels/13dups & 0.18 & 0.15 & 0.04 & -0.13 \\
\hline CNOT4 & No & - & $6.19 \%$ & - & 11 dels/12dups & 0.14 & 3.38 & 1 & 0.81 \\
\hline EXOC4 & No & - & $4.22 \%$ & - & 18dels/18dups/1SNV & -0.09 & -0.27 & 0 & -1.74 \\
\hline FAM180A & No & - & $63.78 \%$ & - & 11dels/11dups & -0.26 & -0.33 & 0.34 & 1.16 \\
\hline$L R G U K$ & No & - & $71.82 \%$ & - & 10dels/12dups & 0.6 & -1.63 & 0 & -1.4 \\
\hline$M T P N$ & No & - & $15.71 \%$ & - & 11dels/11dups & 0.57 & 2.05 & 0.75 & 0.98 \\
\hline NUP205 & Yes & $\begin{array}{l}\text { 616893, nephrotic syndrome, type } \\
13\end{array}$ & $11.40 \%$ & - & 11 dels/12dups/1SNV & -0.77 & 0.87 & 1 & 0.18 \\
\hline SLC13A4 & No & - & $40.17 \%$ & - & 11dels/11dups & 0.64 & 2.16 & 0.92 & -0.96 \\
\hline LUZP6 & No & - & $86.19 \%$ & - & 11dels/11dups & - & - & - & - \\
\hline STRA 8 & No & - & $56.99 \%$ & - & 10dels/11dups & 1.42 & 0.74 & 0 & 0.51 \\
\hline TMEM140 & No & - & $83.19 \%$ & - & 10dels/11dups & -0.01 & -0.05 & 0.04 & - \\
\hline WDR91 & No & - & $46.24 \%$ & - & 10dels/11dups & 0.7 & 1.12 & 0 & 0.51 \\
\hline$S L C 35 B 4$ & No & - & $21.16 \%$ & - & 9dels/12dups & -1.1 & 0.44 & 0 & 0.04 \\
\hline
\end{tabular}

OMIM Online Mendelian Inheritance in Man, HI score Haploinsufficiency Score index-high ranks (e.g., 0-10\%) indicate that a gene is more likely to exhibit haploinsufficiency, and low ranks (e.g., 90-100\%) indicate that a gene is more likely NOT to exhibit haploinsufficiency (retrieved from DECIPHER), $L o F$ loss of function, $C N V s$ copy number variations, $z \mathrm{Z}$ score is the deviation of observed counts from the expected number for one gene (positive $\mathrm{Z}$ scores = gene intolerance to variation, negative $\mathrm{Z}$ scores = gene tolerant to variation) (retrieved from ExAC), $p L I$ probability that a given gene is intolerant of loss-of-function variation ( $\mathrm{pLI}$ closer to one $=$ more intolerant the gene is to LoF variants, $\mathrm{pLI} \geq 0.9$ is extremely LoF intolerant) (retrieved from ExAC), del deletion, dup duplication, $S N V$ single nucleotide variant, ins insertion, indel insertion/deletion

pathogenesis, as this is a common biological theme linking many ID-causative genes. Caldesmon overexpression induced by excess glucocorticoids was described to lead to altered patterns of neuronal radial migration through the reorganization of the cytoskeleton and impact on nervous system structure and function $[29,30]$. Caldesmon is an important regulator of axon development [31] and may also play a role in synaptogenesis, synaptic plasticity, and dendritic arborization [32].

Four of the patients presented larger deletions also affecting the EXOC4 and CNOT4 genes. Considering that patients 1 and 2 are siblings and present the same deletion and very similar phenotypes, the main comparison should be made with patient 4. Concerning the behavioral phenotype, patients 1,2 , and 4 display aggressive behavior, disinhibition, and hyperactivity. Patients 1 and 2 also present some overlapping facial dysmorphisms with those of a patient previously described by Dilzell and colleagues - bulbous nose, thin upper lip, philtrum anomalies, small ears, and low posterior hairline [11]. The deletions' overlap for these four patients is defined by the deletion of patients 1,2 , and 3, resulting in a $2.08-\mathrm{Mb}$ region that includes 15 genes. EXOC4 (EXOCYST COMPLEX COMPONENT 4) is one of the common genes deleted among the first four patients. EXOC4 is the human homolog of Sec8 in yeast. $E X O C 4 / \mathrm{Sec} 8$ encodes a member of the exocyst complex, broadly expressed in rat brain, localized in the synapses, and which plays a role in neurotransmitter release [33]. Sec 8 was described to be involved in the directional movement of 


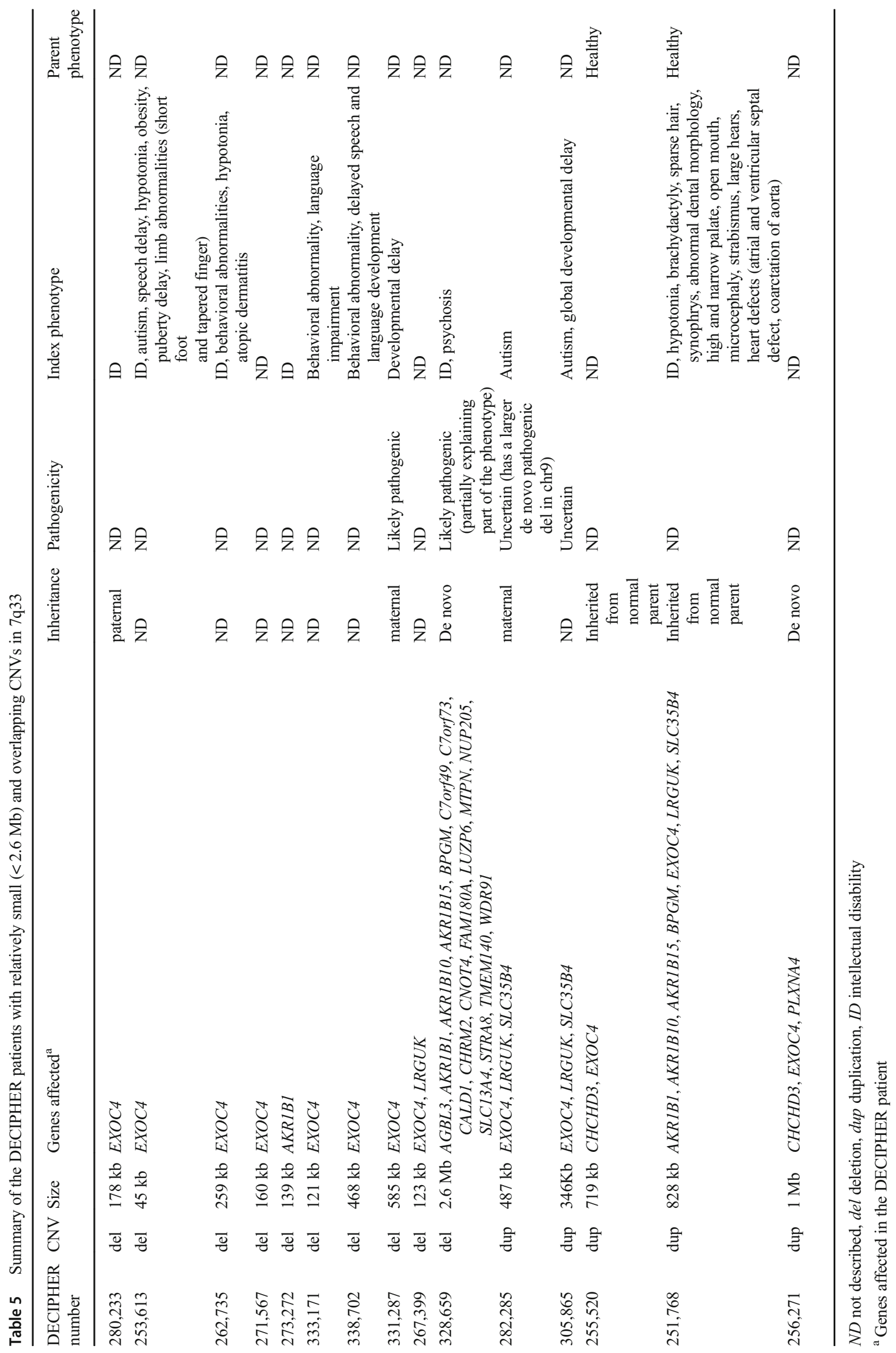


AMPA-type glutamate receptors towards synapses, promoting the membrane communication between polarized cells, as well as in the delivery of NMDA ( $N$-methyl-D-aspartate) receptors to the cell surface in neurons through the interaction of Sec8 PZD domain with synapse-associated protein 102 (SAP102) $[34,35]$. Sec8 was also described to bind to postsynaptic density protein-95 (PSD-95), essential for synaptic function [36].

Yue and colleagues reported a patient with DD and macrocephaly who presented a de novo translocation $\mathrm{t}(7 ; 10)(\mathrm{q} 33 ; \mathrm{q} 23)$, together with a paternal $7-\mathrm{Mb}$ deletion at 7q33. The authors hypothesized that the phenotype might arise due to the resulting EXOC4-PTEN fusion protein and/ or haploinsufficiency of the disrupted genes [3]. The patient had some clinical features in common with the four patients reported here: he also presented ID, delayed speech, hypotonia, and facial dysmorphisms. Unfortunately, a picture is not available in order to allow a comparison with the present cases (Thomas Haaf and Susan Holder, personal communication).

The heterozygous deletion of this gene is thus common to four of the patients here described and to the patient reported by Yue and colleagues. At this point, we can only hypothesize that EXOC4 haploinsufficiency can result in neurotransmission and synaptic impairment, and thus contribute to ID in these patients. However, we cannot disregard that the deletions present in patients $1,2,3$, and 4 encompass other interesting genes.

One of those is the CNOT4 (CCR4-NOT transcription factor complex, subunit 4) gene which encodes a protein that belongs to the conserved Ccr4-Not complex, involved in biological processes such as transcription regulation, mRNA degradation, histone methylation, and DNA repair [37-39]. The disruption of the proper methylation state of several genes has been shown to be associated with several neurodevelopmental disorders (see [40] for revision). In yeast, the CNOT4 homo$\log$ Not4 functions as an E3 ubiquitin ligase and controls the level of Jhd2, the yeast ortholog of JARIDIC [41]. This is interesting since mutations in JARIDIC (lysine-specific demethylase $5 \mathrm{C}$ ) were reported in patients with X-linked ID, revealing that the correct expression of this protein is essential for correct neuronal function [42-44]. Mersman and colleagues demonstrated that in the yeast, JARID1C homolog protein (Jhd2) levels are also regulated by CNOT4 via a polyubiquitin-mediated degradation process [41]. More recently, Not4 was also described to be involved in the regulation of JAK/STAT pathway-dependent gene expression, an important pathway involved in organogenesis and immune and stress response in Drosophila [39]. The International Mouse Phenotyping Consortium [45] reports that mice carrying a homozygous intragenic deletion in Cnot4 present preweaning lethality (with complete penetrance), while the heterozygous mice have an abnormal caudal vertebrae morphology, hematopoiesis, and immune system defects [46]. No mention is made to central nervous system (CNS) or cognitive deficits, or craniofacial features in these mice. However, the literature reports its E3 ubiquitin ligase activity (UPS function being a common theme in neurodevelopmental genetics) and the functional connection to other known ID-causative genes further reinforces the possible contribution of CNOT4 for the phenotype in patients $1,2,3$, and 4 .

Besides the analysis of the candidate genes in the $7 q 33$ affected region, it is also important to take into account the patients described in DECIPHER database [19], with deletions and duplications that partially overlap the 7q33 affected region, summarized in Tables 4 and 5. Regarding the deletions, there are two patients (DECIPHER 280233 and 331287) with small inherited deletions affecting only the EXOC4 gene. Even though for patient 331287 the submitters classified it as likely pathogenic, the phenotypic description of the transmitting progenitor is not provided. Additionally, we became aware of the existence of at least two more patients (unrelated, one with speech delay and the other with ID and hypotonia) carrying small deletions affecting only EXOC4 gene that are inherited from the presumably healthy parents (personal communication by Audrey Briand-Suleau, Cochin Hospital, Paris, France). Concerning the duplications, there are two DECIPHER patients (255520 and 251768) carrying duplications affecting $E X O C 4$, inherited from normal parents. As mentioned before, in these cases, it is important to determine if the duplicated region is located in tandem or not, in order to fully understand the impact of the duplication in the expression of the contained genes. For this reason, the inherited duplications in DECIPHER cases 255520 and 251768 must be interpreted with caution. In the literature, there are few reports of duplication affecting the $7 q 33$ cytoband [2,13]. Although their size is significantly larger than that of the duplication in patients 5,6 , and 7 , the patients with duplications in this region reported by Malmgren and colleagues appear to have a lighter phenotype than those with the corresponding deletion. As for the report of Bartsch and colleagues, both reported patients have a very severe presentation, which might be due to the duplicated region being very large, encompassing the entire genomic region from $7 \mathrm{q} 33$ until the telomere. The difference in size makes the cases reported in these two publications very difficult to compare with patients 5,6 , and 7 .

In the Database of Genomic Variants (DGVs), there are no deletions as large as the one present in patient 4. As for the duplicated region, there are no similar duplications in DGV. There are three small deletions in this region (affecting AGBL3, CALD1, and TMEM140 genes); however, the presence of these deletions should be interpreted with care, as many of these large studies of control populations might have false calls and/or affected individuals as controls and they cannot be the basis of exclusion of a candidate alteration, especially in the light of other genetic and functional evidence supporting its relevance. 
Nevertheless, these six cases raise doubts about the straightforward contribution of EXOC4 for the NDD phenotype, leaving $A G B L 3, C N O T 4$, and $C A L D 1$ as the more promising candidates.

In summary, this work presents seven patients with interstitial $7 \mathrm{q} 33 \mathrm{CNVs}$ and suggests that EXOC4, CNOT4, $A G B L 3$, and $C A L D 1$ genes are likely contributing for ID and a behavioral phenotype, characterized by aggressiveness and disinhibition. CNVs could impact the phenotype observed in these patients not only by means of haploinsufficiency but also due to the formation of chimeric genes, as the one observed in the patients with the duplication. Chimeras may disrupt critical brain processes, including neurogenesis, neuronal differentiation, and synapse formation, supporting the idea that chimeric genes play a role in the illness, at least in a small number of affected individuals, as recent publications have illustrated [22, 47]. Further studies need to be performed in order to better understand the contribution of each gene within this region to the phenotype.

Acknowledgements We would like to thank all the patients and their families for their participation in the genetic studies and for allowing this publication. We would also like to acknowledge the DECIPHER Consortium, Database of Genomic Variants, and OMIM since this study makes use of data generated by these platforms.

Author contribution FL, FT, SS, and PR performed the molecular studies and analyzed the molecular data. AMF, SAL, AJ, and JS collected clinical data. FL, FT, and PM drafted the paper. PM obtained funding for this study. The study was performed under the direction of PM.

Funding information This work has been funded by FEDER funds, through the Competitiveness Factors Operational Programme (COMPETE), and by National funds, through the Foundation for Science and Technology (FCT), under the scope of the projects PIC/IC/83026/ 2007, PIC/IC/83013/2007, and POCI-01-0145-FEDER-007038. This work has also been funded by the project NORTE-01-0145-FEDER000013, supported by the Northern Portugal Regional Operational Programme (NORTE 2020), under the Portugal 2020 Partnership Agreement, through the European Regional Development Fund (FEDER). FL was supported by Foundation for Science and Technology (FCT) through the fellowship SFRH/BD/90167/2012.

\section{Compliance with ethical standards}

Competing interests The authors declare that they have no conflict of interest.

\section{References}

1. Xu Z, Geng Q, Luo F, Xu F, Li P, Xie J (2014) Multiplex ligationdependent probe amplification and array comparative genomic hybridization analyses for prenatal diagnosis of cytogenomic abnormalities. Mol Cytogenet 7(1):84. https://doi.org/10.1186/s13039014-0084-5

2. Malmgren H, Malm G, Sahlén S, Karlsson M, Blennow E (2005) Molecular cytogenetic characterization of an insertional translocation, ins(6;7)(p25;q33q34): deletion/duplication of 7q33-34 and clinical correlations. Am J Med Genet A 139(1):25-31. https:// doi.org/10.1002/ajmg.a.30983

3. Yue Y, Grossmann B, Holder SE, Haaf T (2005) De novo $\mathrm{t}(7 ; 10)(\mathrm{q} 33 ; \mathrm{q} 23)$ translocation and closely juxtaposed microdeletion in a patient with macrocephaly and developmental delay. Hum Genet 117(1):1-8. https://doi.org/10.1007/s00439005-1273-4

4. Mitchell S, Siegel DH, Shieh JTC, Stevenson DA, Grimmer JF, Lewis T, Metry D, Frieden I, Blei F, Kayserili H, Drolet BA, Bayrak-Toydemir P (2012) Candidate locus analysis for PHACE syndrome. Am J Med Genet A 158A(6):1363-1367. https://doi. org/10.1002/ajmg.a.35341

5. Rossi E, Verri AP, Patricelli MG, Destefani V, Ricca I, Vetro A, Ciccone R, Giorda R, Toniolo D, Maraschio P, Zuffardi O (2008) A $12 \mathrm{Mb}$ deletion at $7 \mathrm{q} 33-\mathrm{q} 35$ associated with autism spectrum disorders and primary amenorrhea. Eur J Med Genet 51(6):631-638. https://doi.org/10.1016/j.ejmg.2008.06.010

6. Petrin AL, Giacheti CM, Maximino LP, Abramides DVM, Zanchetta S, Rossi NF, Richieri-Costa A, Murray JC (2010) Identification of a microdeletion at the 7q33-q35 disrupting the CNTNAP2 gene in a Brazilian stuttering case. Am J Med Genet A 152A(12):3164-3172. https://doi.org/10.1002/ajmg.a.33749

7. Ponnala R, Dalal A (2011) Partial monosomy 7q. Indian Pediatr 48(5):399-401

8. Verma RS, Conte RA, Sayegh SE, Kanjilal D (1992) The interstitial deletion of bands q33-35 of long arm of chromosome 7: a review with a new case report. Clin Genet 41(2):82-86

9. Stallard R, Juberg RC (1981) Partial monosomy 7q syndrome due to distal interstitial deletion. Hum Genet 57(2):210-213

10. Nielsen KB, Egede F, Mouridsen I, Mohr J (1979) Familial partial $7 \mathrm{q}$ monosomy resulting from segregation of an insertional chromosome rearrangement. J Med Genet 16(6):461-466. https://doi.org/ 10.1136/jmg. 16.6.461

11. Dilzell K, Darcy D, Sum J, Wallerstein R (2015) Deletion of 7q33q35 in a patient with intellectual disability and dysmorphic features: further characterization of $7 \mathrm{q}$ interstitial deletion syndrome. Case Rep Genet 2015:131852-131855. https://doi.org/10.1155/2015/ 131852

12. Kale T, Philip M (2016) An interstitial deletion at 7q33-36.1 in a patient with intellectual disability, significant language delay, and severe microcephaly. Case Rep Genet 2016:6046351. https://doi. org/10.1155/2016/6046351

13. Bartsch O, Kalbe U, Ngo TK et al (1990) Clinical diagnosis of partial duplication 7q. Am J Med Genet 37(2):254-257. https:// doi.org/10.1002/ajmg.1320370218

14. Krijgsman O, Israeli D, van Essen HF, Eijk PP, Berens MLM, Mellink CHM, Nieuwint AW, Weiss MM, Steenbergen RDM, Meijer GA, Ylstra B (2013) Detection limits of DNA copy number alterations in heterogeneous cell populations. Cell Oncol Dordr 36(1):27-36. https://doi.org/10.1007/s13402-012-0108-2

15. Buffart TE, Israeli D, Tijssen M, Vosse SJ, Mršić A, Meijer GA, Ylstra B (2008) Across array comparative genomic hybridization: a strategy to reduce reference channel hybridizations. Genes Chromosomes Cancer 47(11):994-1004. https://doi.org/10.1002/ gcc. 20605

16. Jovanovic L, Delahunt B, McIver B et al (2003) Optimising restriction enzyme cleavage of DNA derived from archival histopathological samples: an improved HUMARA assay. Pathology (Phila) 35: 70-74

17. Hoebeeck J, van der Luijt R, Poppe B, de Smet E, Yigit N, Claes K, Zewald R, de Jong GJ, de Paepe A, Speleman F, Vandesompele J (2005) Rapid detection of VHL exon deletions using real-time quantitative PCR. Lab Investig J Tech Methods Pathol 85(1):24 33. https://doi.org/10.1038/labinvest.3700209

18. Wechsler D (1991) Wechsler intelligence scale for children - third edition 
19. Firth HV, Richards SM, Bevan AP, Clayton S, Corpas M, Rajan D, Vooren SV, Moreau Y, Pettett RM, Carter NP (2009) DECIPHER: database of chromosomal imbalance and phenotype in humans using Ensembl resources. Am J Hum Genet 84(4):524-533. https://doi.org/10.1016/j.ajhg.2009.03.010

20. Newman S, Hermetz KE, Weckselblatt B, Rudd MK (2015) Nextgeneration sequencing of duplication CNVs reveals that most are tandem and some create fusion genes at breakpoints. Am J Hum Genet 96(2):208-220. https://doi.org/10.1016/j.ajhg.2014.12.017

21. Huang N, Lee I, Marcotte EM, Hurles ME (2010) Characterising and predicting haploinsufficiency in the human genome. PLoS Genet 6(10):e1001154. https://doi.org/10.1371/journal.pgen. 1001154

22. Rippey C, Walsh T, Gulsuner S, Brodsky M, Nord AS, Gasperini M, Pierce S, Spurrell C, Coe BP, Krumm N, Lee MK, Sebat J, McClellan JM, King MC (2013) Formation of chimeric genes by copy-number variation as a mutational mechanism in schizophrenia. Am J Hum Genet 93(4):697-710. https://doi.org/10.1016/j. ajhg.2013.09.004

23. Córdova-Fletes C, Domínguez MG, Delint-Ramirez I, MartínezRodríguez HG, Rivas-Estilla AM, Barros-Núñez P, Ortiz-López R, Neira VA (2015) A de novo t(10;19)(q22.3; 13.33$)$ leads to ZMIZ1/PRR12 reciprocal fusion transcripts in a girl with intellectual disability and neuropsychiatric alterations. Neurogenetics 16(4):287-298. https://doi.org/10.1007/s10048-015-0452-2

24. Tort O, Tanco S, Rocha C, Bieche I, Seixas C, Bosc C, Andrieux A, Moutin MJ, Aviles FX, Lorenzo J, Janke C (2014) The cytosolic carboxypeptidases CCP2 and CCP3 catalyze posttranslational removal of acidic amino acids. Mol Biol Cell 25(19):3017-3027. https://doi.org/10.1091/mbc.E14-06-1072

25. Rogowski K, Van DJ, Magiera MM et al (2010) A family of protein-Deglutamylating enzymes associated with neurodegeneration. Cell 143(4):564-578. https://doi.org/10.1016/j.cell.2010.10. 014

26. GTEx Portal. http://www.gtexportal.org/home/. Accessed 25 Feb 2017

27. Lin JJ-C, Li Y, Eppinga RD et al (2009) Chapter 1: roles of caldesmon in cell motility and actin cytoskeleton remodeling. Int Rev Cell Mol Biol 274:1-68. https://doi.org/10.1016/S19376448(08)02001-7

28. Mayanagi T, Sobue K (2011) Diversification of caldesmon-linked actin cytoskeleton in cell motility. Cell Adhes Migr 5(2):150-159. https://doi.org/10.4161/cam.5.2.14398

29. Fukumoto K, Morita T, Mayanagi T, Tanokashira D, Yoshida T, Sakai A, Sobue K (2009) Detrimental effects of glucocorticoids on neuronal migration during brain development. Mol Psychiatry 14(12):1119-1131. https://doi.org/10.1038/mp.2009.60

30. Mayanagi T, Morita T, 'ichiro HK et al (2008) Glucocorticoid receptor-mediated expression of caldesmon regulates cell migration via the reorganization of the actin cytoskeleton. J Biol Chem 283(45):31183-31196. https://doi.org/10.1074/jbc.M801606200

31. Morita T, Mayanagi T, Sobue K (2012) Caldesmon regulates axon extension through interaction with myosin II. J Biol Chem 287(5): 3349-3356. https://doi.org/10.1074/jbc.M111.295618

32. Sobue K, Fukumoto K (2010) Caldesmon, an actin-linked regulatory protein, comes across glucocorticoids. Cell Adhes Migr 4(2): 185-189. https://doi.org/10.4161/cam.4.2.10886
33. Hsu SC, Ting AE, Hazuka CD, Davanger S, Kenny JW, Kee Y, Scheller RH (1996) The mammalian brain rsec6/8 complex. Neuron 17(6):1209-1219. https://doi.org/10.1016/S08966273(00)80251-2

34. Gerges NZ, Backos DS, Rupasinghe CN, Spaller MR, Esteban JA (2006) Dual role of the exocyst in AMPA receptor targeting and insertion into the postsynaptic membrane. EMBO J 25(8):16231634. https://doi.org/10.1038/sj.emboj.7601065

35. Sans N, Prybylowski K, Petralia RS, Chang K, Wang YX, Racca C, Vicini S, Wenthold RJ (2003) NMDA receptor trafficking through an interaction between PDZ proteins and the exocyst complex. Nat Cell Biol 5(6):520-530. https://doi.org/10.1038/ncb990

36. Riefler GM, Balasingam G, Lucas KG et al (2003) Exocyst complex subunit $\sec 8$ binds to postsynaptic density protein-95 (PSD95): a novel interaction regulated by cypin (cytosolic PSD-95 interactor). Biochem J 373(1):49-55. https://doi.org/10.1042/ BJ20021838

37. Kruk JA, Dutta A, Fu J, Gilmour DS, Reese JC (2011) The multifunctional Ccr4-not complex directly promotes transcription elongation. Genes Dev 25(6):581-593. https://doi.org/10.1101/gad. 2020911

38. Collart MA (2003) Global control of gene expression in yeast by the Ccr4-not complex. Gene 313:1-16. https://doi.org/10.1016/ S0378-1119(03)00672-3

39. Grönholm J, Kaustio M, Myllymäki H et al (2012) Not4 enhances JAK/STAT pathway-dependent gene expression in drosophila and in human cells. FASEB J Off Publ Fed Am Soc Exp Biol 26(3): 1239-1250. https://doi.org/10.1096/fj.11-195875

40. Rudenko A, Tsai L-H (2014) Epigenetic modifications in the nervous system and their impact upon cognitive impairments. Neuropharmacology 80:70-82. https://doi.org/10.1016/j. neuropharm.2014.01.043

41. Mersman DP, Du H-N, Fingerman IM, South PF, Briggs SD (2009) Polyubiquitination of the demethylase Jhd 2 controls histone methylation and gene expression. Genes Dev 23(8):951-962. https://doi. org/10.1101/gad.1769209

42. Abidi F, Holloway L, Moore CA et al (2009) Novel human pathological mutations. Gene symbol: JARID1C. Disease: mental retardation, X-linked. Hum Genet 125:344

43. Ounap K, Puusepp-Benazzouz H, Peters M et al (2012) A novel c.2T > C mutation of the KDM5C/JARID1C gene in one large family with X-linked intellectual disability. Eur J Med Genet 55(3):178-184. https://doi.org/10.1016/j.ejmg.2012.01.004

44. Brookes E, Laurent B, Õunap K, Carroll R, Moeschler JB, Field M, Schwartz CE, Gecz J, Shi Y (2015) Mutations in the intellectual disability gene $\mathrm{KDM} 5 \mathrm{C}$ reduce protein stability and demethylase activity. Hum Mol Genet 24(10):2861-2872. https://doi.org/10. 1093/hmg/ddv046

45. IMPC | International Mouse Phenotyping Consortium. http://www. mousephenotype.org/. Accessed 21 Sep 2017

46. Cnot4 MGI Mouse Gene Detail - MGI:1859026 - CCR4-NOT transcription complex, subunit 4. http://www.informatics.jax.org/ marker/MGI:1859026. Accessed 14 Apr 2017

47. Mayo S, Monfort S, Roselló M, Orellana C, Oltra S, Caro-Llopis A, Martínez F (2017) Chimeric genes in deletions and duplications associated with intellectual disability. Int J Genomics 2017: 4798474. https://doi.org/10.1155/2017/4798474 